fors

Journal of Engineering Science and Technology Review 3 (1) (2010) 200-209
JOURNAL OF

Engineering Science and

Technology Review

Research Article

\title{
A Study of Wind Farm Stabilization Using DFIG or STATCOM Considering Grid Requirements
}

\author{
K. E Okedu* \\ Department of Electrical/Electronic Engineering, University of Port Harcourt, Nigeria.
}

Received 16 March 2010; Revised 3 June 2010; Accepted 6 December 2010

\begin{abstract}
Recently, the grid codes require taking into account the reactive power of the wind farm in order to contribute to the network stability, thus operating the wind farm as active compensator devices. This paper presents a comparative study of stabilizing a wind farm using (Doubly Fed Induction Generators) DFIGs or using a (Static Synchronous Compensator) STATCOM during wind speed change and grid fault. Simulation results show that the wind farm could be effectively stabilized with both systems, but at a reduced cost with the DFIGs system because it can provide reactive power through its frequency converters without an external reactive power compensation unit like the STATCOM system significant.
\end{abstract}

Keywords: DFIG, STATCOM, Grid Codes, Stability, Grid Fault, Wind Farm.

\section{Introduction}

It is increasingly important that wind generation continue to operate during periods of short circuit fault in the grid. The penetration of wind power has reached levels high enough to affect the quality and stability of the grid [3]. According to grid codes issued by utilities, tripping of wind turbines following grid fault is not allowed. Besides to provide voltage support to the grid, mandatory reactive current supply is necessary [1]. Main ancillary services in a power system are power-frequency control and voltage control. These services must be provided by each generator connected to the grid. In order to provide the ancillary service of voltage, generators must have some reactive power capability as required by the corresponding grid codes [7].

Recently, the most widely used variable wind turbine is the Doubly Fed Induction Generator type (DFIG) because it can operate at a wider range of speed depending on the wind speed or other specific operation requirements. Thus it allows for a better capture of wind energy $[4,12,14]$, and dynamic slip control and pitch control may contribute to rebuilding the voltage at the wind turbine terminals and maintaining the power system stability after clearance of an external short-circuit fault [2]. In addition, DFIG have shown better behavior concerning system stability during short-circuit faults in comparison to IG, because of its capability of decoupling the control of output active and reactive power. The superior dynamic performance of the DFIG results from the frequency converter which typically operates with sampling and switching frequencies of above $2 \mathrm{kHz}$ [1]. At lower voltages down to $0 \%$ during grid fault, the IGBTs (Insulated Gate Bipolar Transistors) of the DFIG are switched off and the system remains in standby mode $[9-11,13]$. If the voltages are above a certain threshold value during fault, the DFIG system is very quickly synchronized and is back in operation again.

On the other hand, Static Synchronous Compensators (STAT$\mathrm{COM}$ ) can be use to provide reactive power to stabilize a wind farm also. There are various voltage source or current source inverter based on FACTS devices for flexible power control damping of power system and stabilization of wind generators $[15,16]$, but in this work STATCOM based on a voltage source converter (VSC) PWM technique is used to stabilize the IGs in the wind farm in comparison to the use of the DFIGs.

This paper presents a comparative analysis of the use of DFIGs or STATCOM to stabilize a wind farm. Simulation model of wind turbine with DFIGs and IGs developed in PSCAD/EMTDC [17] is presented.

\section{Model System}

The model system for this work is shown in Figures 1(a-c) where in case 1; the Wind Farm is composed of 2 aggregated DFIGs each of capacity 12.5MVA, and 2 IGs (Induction Generators) each of capacity $12.5 \mathrm{MVA}$. The 2 DFIGs were used to stabilize the wind farm by connecting them to the two IGs and then to an infinite bus (Figure 1a).

In case 2, the capacity of the wind farm considered is half of that of case 1 , because no DFIGs were connected to the IGs and also no reactive power compensation unit was installed (Figure 1b) 
for stabilization of the wind farm.

Finally, in Case 3, a STATCOM was used for the stabilization of the wind farm by connecting it to the Point of Common Coupling (PCC) of the 2 IGs and then to the infinite bus. The STAT$\mathrm{COM}$ has the ability of providing reactive power to the system like the 2 DFIGs in case 1.In this case, the capacity of the wind farm is also half of that of case 1 (Figure 1c).

Table1 shows the parameters of the IGs and the DFIGs wind turbine used in this study [6].

Table 1. Parameters of the Generators.

\begin{tabular}{lll}
\hline Generator Type & IGs & DFIGs \\
\hline Rated Voltage & $690 \mathrm{~V}$ & $690 \mathrm{~V}$ \\
Stator Resistance & $0.01 \mathrm{pu}$ & $0.01 \mathrm{pu}$ \\
Stator Leakage Reactance & $0.07 \mathrm{pu}$ & $0.15 \mathrm{pu}$ \\
Magnetizing Reactance & $4.1 \mathrm{pu}$ & $3.5 \mathrm{pu}$ \\
Rotor Resistance & $0.007 \mathrm{pu}$ & $0.01 \mathrm{pu}$ \\
Rotor leakage Reactance & $0.07 \mathrm{pu}$ & $0.15 \mathrm{pu}$ \\
Inertia Constant & $1.5 \mathrm{secs}$ & $1.5 \mathrm{secs}$ \\
\hline
\end{tabular}

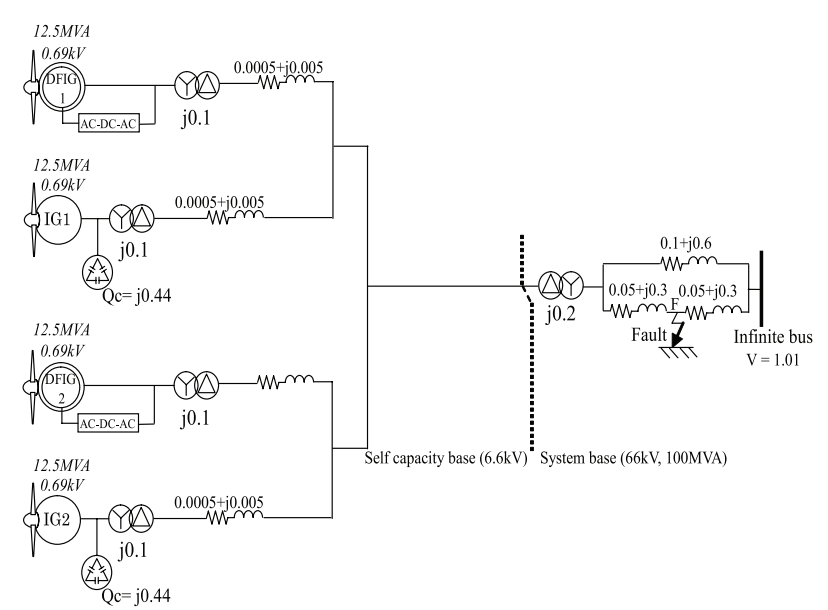

Figure 1a. Wind farm stabilization using DFIGs (Case 1)

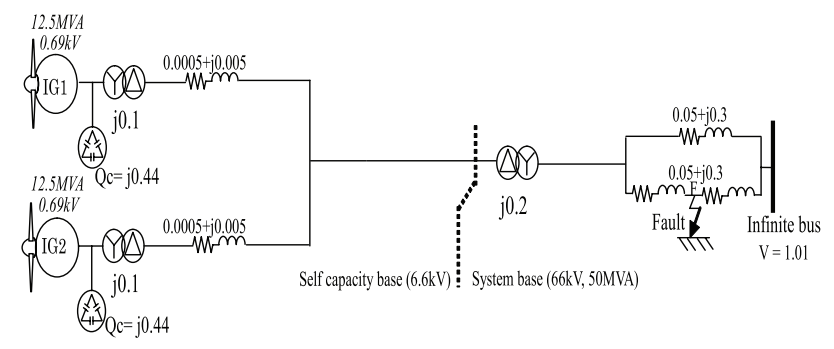

Figure 1b. Wind farm with no stabilization device (Case 2)

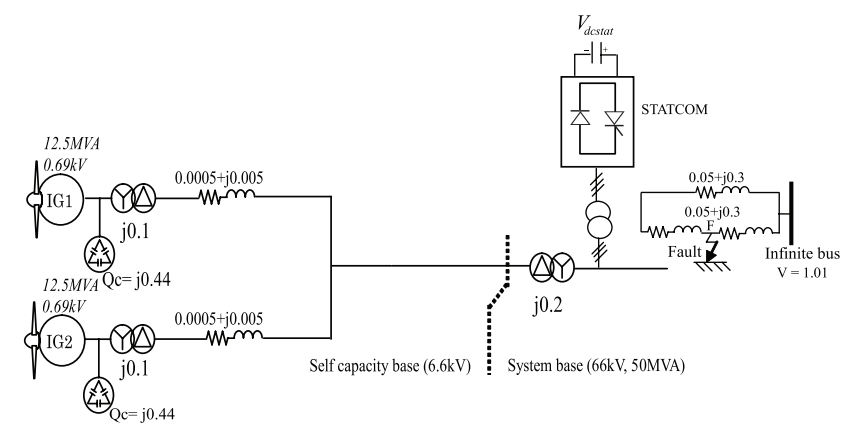

Figure 1c. Wind farm stabilization using STATCOM (Case 3)
In all cases, a three line to ground (3LG) symmetrical grid fault is said to occur as shown in the model system.

\section{Grid Requirements}

Grid codes describes the minimum technical and organizational requirements that most be fulfilled when setting up and operating grid connections. They are aim firstly at the objective requirements for fault-free operation of the grid, and secondly on the importance of plant operation in line with requirements for the connectee [8].

The main requirements established in these new grid codes are the so-called wind turbine low voltage ride through capability and reactive power capability [7]. The first specification aims to improve transient stability in a power system with a high penetration of wind energy, while the second specification aims to support voltage control in such power system. Thus the wind farm should have the capability to control the voltage and or reactive power at the connection point. This is essential in order to ensure secure operation of the system.

Figure 2 shows the limit curves (red lines) for the voltage patterns at the grid connection for a generating plant; where three phase short circuits or fault related symmetrical voltage dip must not lead to instability above limits line 1 or to disconnection of the generating plant from the grid after limit line 2 as set by German E.on netz [8].

Figure 3 shows the required reactive current support from the generating plants during voltage dip for overexcited and under excited operations as set by German E.on netz [8].

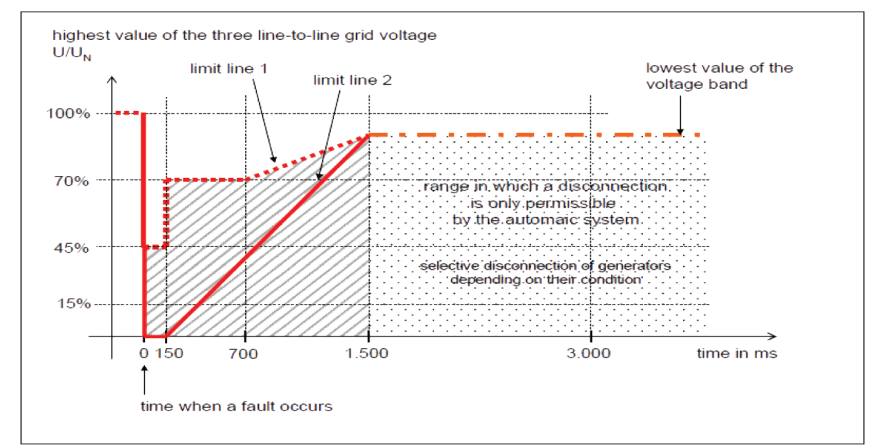

Figure 2. Fault ride through requirement for wind farm (by E.ON NETZ)

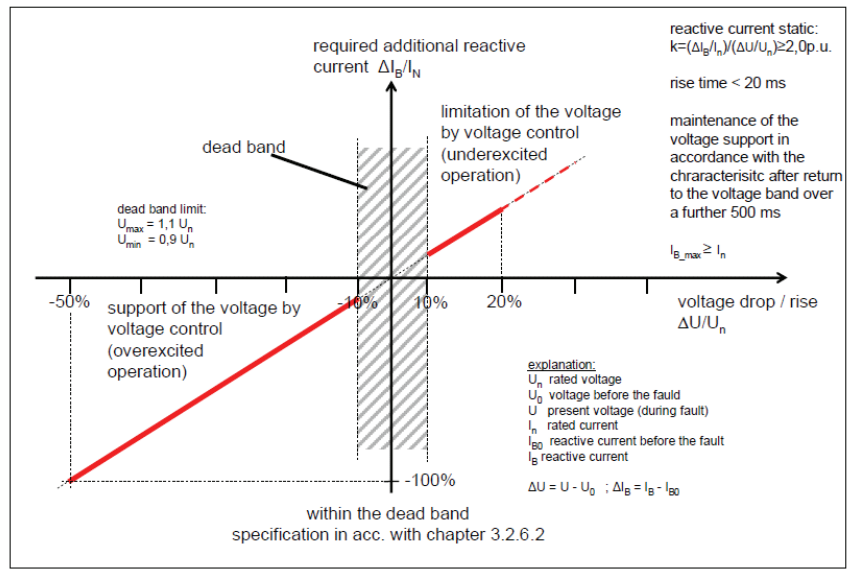

Figure 3. Limit curves for the voltage pattern during grid fault (by E.ON NETZ) 


\section{DFIG Wind Turbine Model and Control}

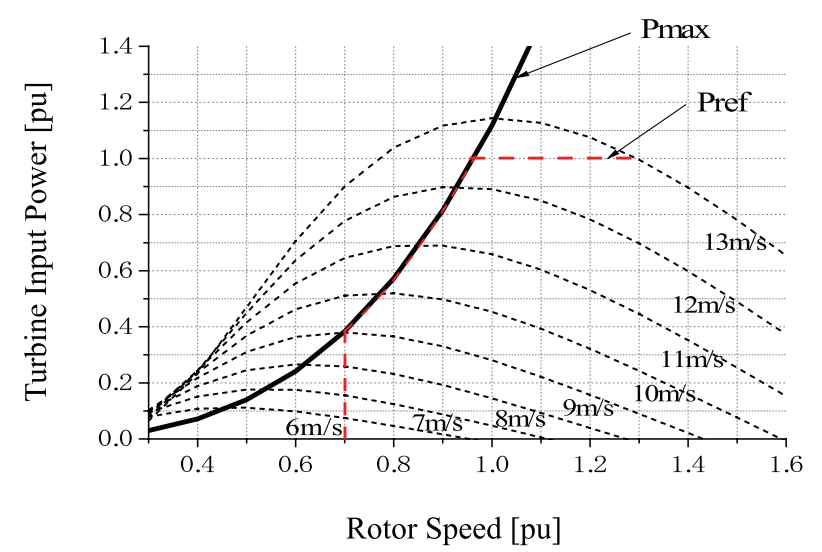

Figure 4. Turbine characteristic with maximum power point tracking for DFIG

Figure 4 above shows wind turbine characteristic used for this study with the turbine input power plotted against the rotor speed of the turbine. The range of operation of the variable speed DFIG turbine is designed to follow the dotted red line from $0.7 \mathrm{pu}$ for minimum speed to $1.3 \mathrm{pu}$ for maximum speed.

The maximum power that can be obtained from the DFIG wind turbine at various wind speed from $6-13 \mathrm{~m} / \mathrm{s}$ is given by the locus Pmax in Figure 4. The rated speed of the turbine from Fig. 4 is gotten by tracing the line at 1.0pu turbine input power to the various speed curves, which gives 12.43 and at a rated rotor speed of $0.96 \mathrm{pu}$.

The equations for the modeling of the wind turbine are described as follows.

The captured power from the wind can be expressed as eqn (1). Tip speed ratio, $\lambda$ and power coefficient, $C_{p}$ can be expressed as eqs. (2) and (3) as shown below [5, 6].

$P_{w t b}=0.5 \rho C_{\rho}(\lambda, \beta) \pi R^{2} V_{w}^{3}[W]$

$C_{\rho}(\lambda, \beta)=0.5\left(\Gamma-0.022 \beta^{2}-5.6\right) e^{-0.17 \Gamma}$

$\lambda=\frac{w_{w t b} R}{V_{w}}$

$\Gamma=\frac{R(3600)}{\lambda(1609)}$

The torque coefficient and the turbine torque are expressed as follows.

$$
\begin{aligned}
& C_{t}=\frac{C_{p}(\lambda)}{\lambda} \\
& T_{M}=0.5 \rho C_{t}(\lambda) \pi R^{3} V_{w}^{2}[\mathrm{NM}]
\end{aligned}
$$

Where, $P_{w t b}$ is the extracted power from the wind, $\rho$ is the air density $\left[\mathrm{kg} / \mathrm{m}^{3}\right], \mathrm{R}$ is the blade radius $[\mathrm{m}], V_{w}$ is wind speed $[\mathrm{m} / \mathrm{s}]$, blade pitch angle is $\beta$ [deg], $\omega_{w t b}$ is the rotational speed [ $\left.\mathrm{rad} / \mathrm{s}\right]$, and $T_{M}$ is the wind turbine output torque [Nm].

The Pitch angle controller of the DFIG system which helps to achieve the minimum and maximum limit of the rotor speed during wind speed change and grid fault is shown in Figure 5 below.

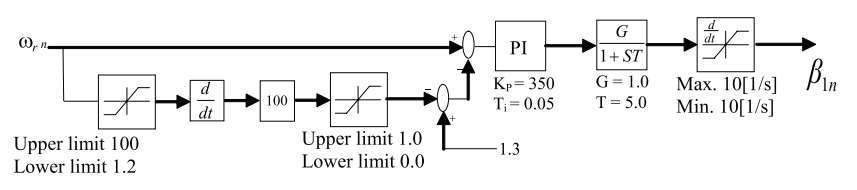

Figure 5. Pitch Angle Controller for the DFIGs

In Figure 5 above, when the rotor speed exceeds 1.2pu due to high wind speed, the control system activates to limit the rotor speed to a maximum value of $1.3 \mathrm{pu}$ through the proportionate integral (PI) controller and the gain function block at a maximum and minimum limiter value of $10 \mathrm{deg} / \mathrm{sec}$.

The DFIG wind turbine control system is divided into two parts; the rotor side converter (RSC) and the grid side converter (GSC). The control blocks for both converters are shown in Figure 6. From Figure 6, the rotor side converter controls the terminal (grid) voltage to $1.01 \mathrm{pu}$. The d-axis current (Id) controls the active power (PDFIG), while the q-axis current (Iq) controls the reactive power of the DFIG. After dq0-to-abc transformation, $V_{d r}{ }^{*}$ and $V_{q r}{ }^{*}$ are sent to the PWM signal generator and $V_{a b c}{ }^{*}$ are the three-phase voltages desired at the rotor side converter output as shown in the converter configuration circuit.

Also for the GSC, the direct axis (Id) component is used to regulate the dc-link voltage $\left(E_{d c}\right)$ to $1.0 \mathrm{pu}$. The d-axis current controls the DC-Link voltage, while the q-axis current (Iq) controls the reactive power of the grid side converter. After a dq0- toabc transformation, $V_{q}^{*}$ and $V_{d}^{*}$ are sent to the PWM signal generator. Finally $V_{a b c}{ }^{*}$ are three voltages at the GSC output for the IGBT's switching with a carrier frequency of $2 \mathrm{kHz}$. The circuit configuration of the rotor side, dc-link and the grid-side converter

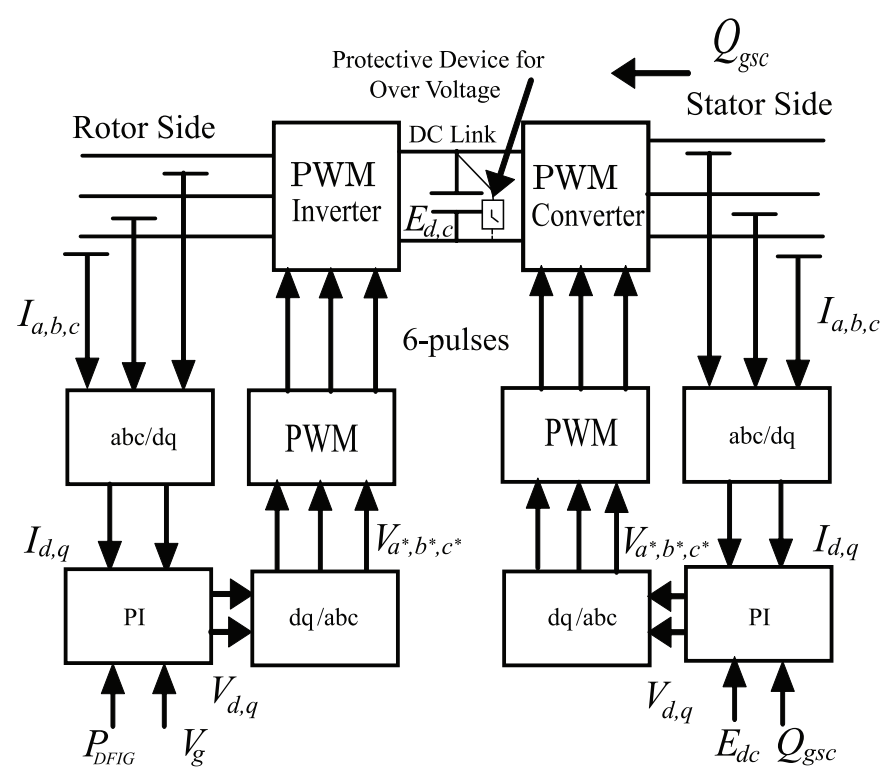

Figure 6. Circuit configuration of power converter of DFIG 
of the DFIG is given in Figure 6, while Table 2 gives the ratings of the excitation circuit of the DFIG used for this study.

Table 2. Ratings and Parameters of Excitation Circuit of DFIGs.

\begin{tabular}{lc}
\hline DC link voltage & $1.5 \mathrm{kV}$ \\
Dc link capacitor & $50,000 \mu \mathrm{F}$ \\
Device for power converter & IGBT \\
PWM carrier frequency & $2 \mathrm{kHz}$ \\
Upper limit of DC voltage (EDC_MAX) & $1.80 \mathrm{kV}(120 \%$ of rating $)$ \\
Lower limit of DC voltage (EDC_MIN) & $0.75 \mathrm{kV}(50 \%$ of rating) \\
$\begin{array}{l}\text { Short circuit parameter of protective } \\
\text { device for over voltage }\end{array}$ & $0.2 \mathrm{ohm}$ \\
\hline
\end{tabular}

\section{STATCOM Control System}

STATCOM can enhance the transient stability and significantly minimize the blade-shaft torsion oscillation of wind turbine generators [16]. The reactive power of a STATCOM is produced by means of power electronic equipment of the voltage source converter (VSC) type.

The VSC converts the dc voltage into a three-phase set of output voltages with desired amplitude, frequency and phase. The control scheme for the STATCOM used in case 3 is shown in Figure 7, where the d-axis current (Idstat) controls the STATCOM DC-link voltage (VSTAT) to a constant value of $1.0 \mathrm{pu}$, as that of the DC-link voltage of the DFIG system used in case 1, while the q-axis current (Iqstat) controls the reactive power of the STATCOM to maintain a terminal (grid) voltage of $1.01 \mathrm{pu}$ as that of the DFIG system in case 1 respectively.

In Figure 7 schematic diagram for the STATCOM switching circuit, after a dq/abc transformation as that done in the DFIG system, the triangular carrier signal of $1.05 \mathrm{kHz}$ is used for the PWM operation. Table 3 displays the parameters of the STATCOM used for this study.

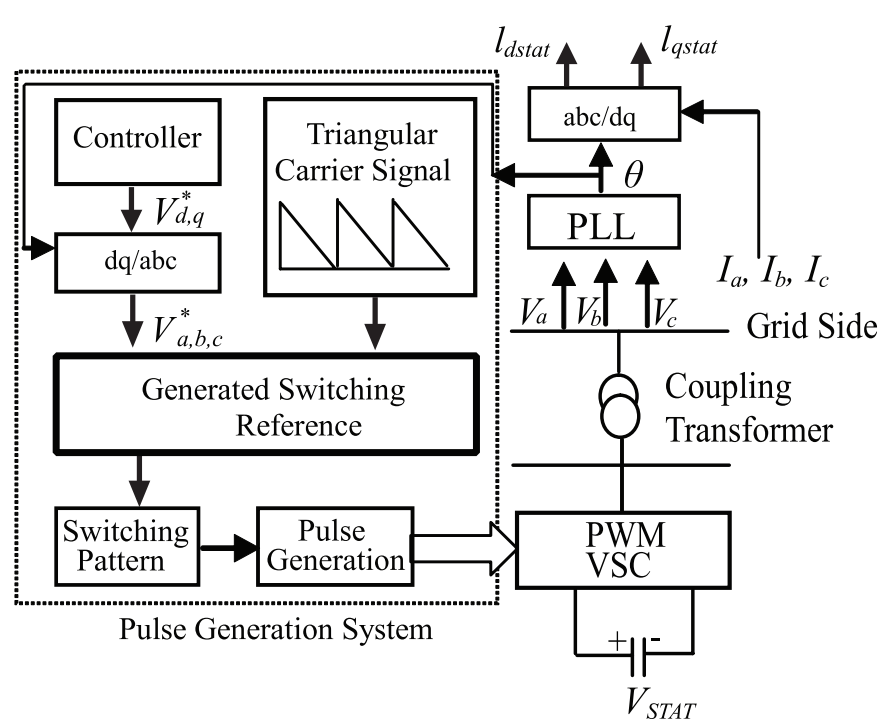

Figure 7. Schematic diagram of a STATCOM switching circuit
Table 3. Parameters of STATCOM.

\begin{tabular}{lc}
\hline DC link voltage & $6.6 \mathrm{kV}$ \\
Dc link capacitor & $50,000 \mu \mathrm{F}$ \\
Device for power converter & $\mathrm{IGBT}$ \\
PWM carrier frequency & $1.05 \mathrm{kHz}$ \\
Rated Power & $25 \mathrm{MVA}$ \\
Rated Voltage & $3.50 \mathrm{kV}$ \\
\hline
\end{tabular}

\section{Simulation Results}

Simulations were run in PSCAD/EMTDC [17] for 600sec. for the three cases with different real wind speed data obtained from Hokkaido Island, Japan, for each generator. The response of the wind farm to wind speed change are shown in Figures 8-23. The wind farm responses during grid fault are given in Figures 2438 where simulations were run for $10 \mathrm{sec}$. with three phase fault applied at $0.1 \mathrm{sec}$, as shown in the model system, and the circuit breakers on the faulted line were opened and reclosed at $0.2 \mathrm{sec}$ and $1.0 \mathrm{sec}$ respectively. During the fault analysis, for case 1 , the DFIGs and the IGs are at constant velocity of $15 \mathrm{~m} / \mathrm{s}$, while for cases 2 and 3, the IGs are at their rated fixed speed.

\section{A) Response of Wind Farm to Wind Changes}

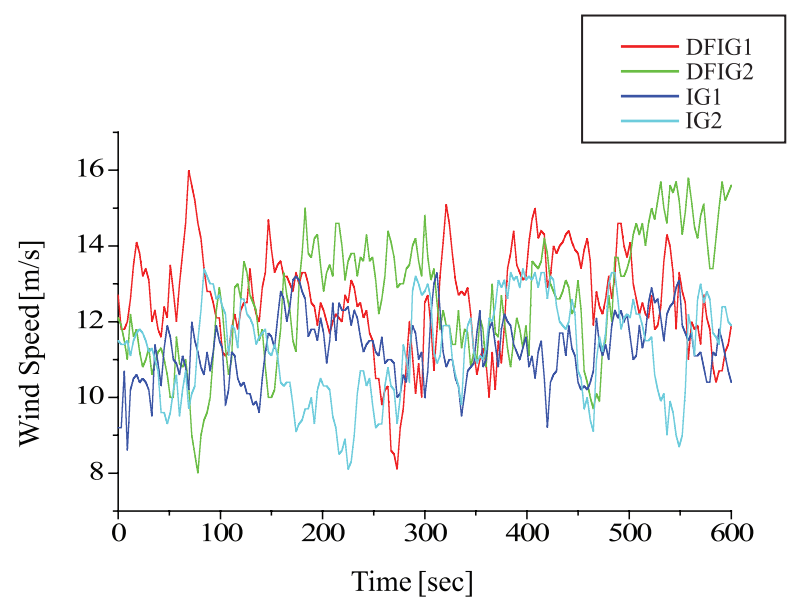

Figure 8. Wind Speed for DFIGs and IGs (All cases)

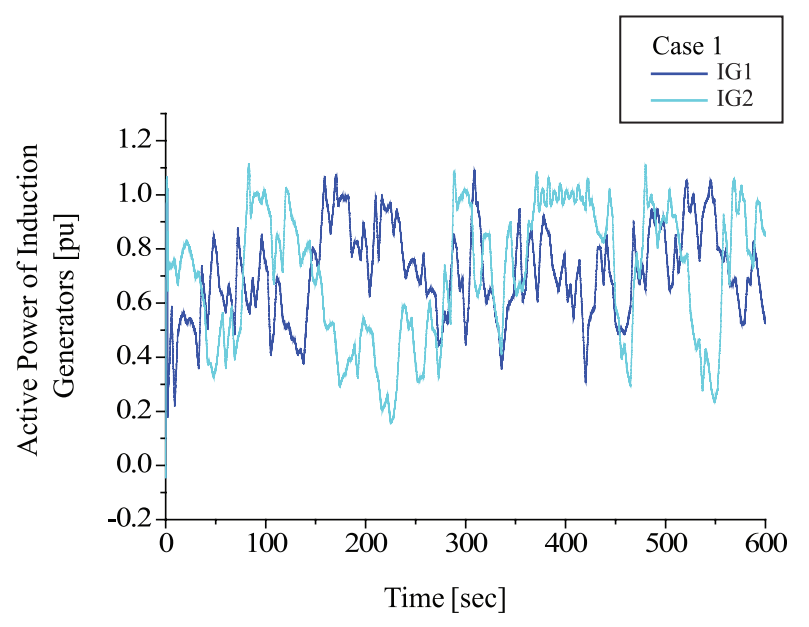

Figure 9. Active Power of Induction Generators (Case 1) 


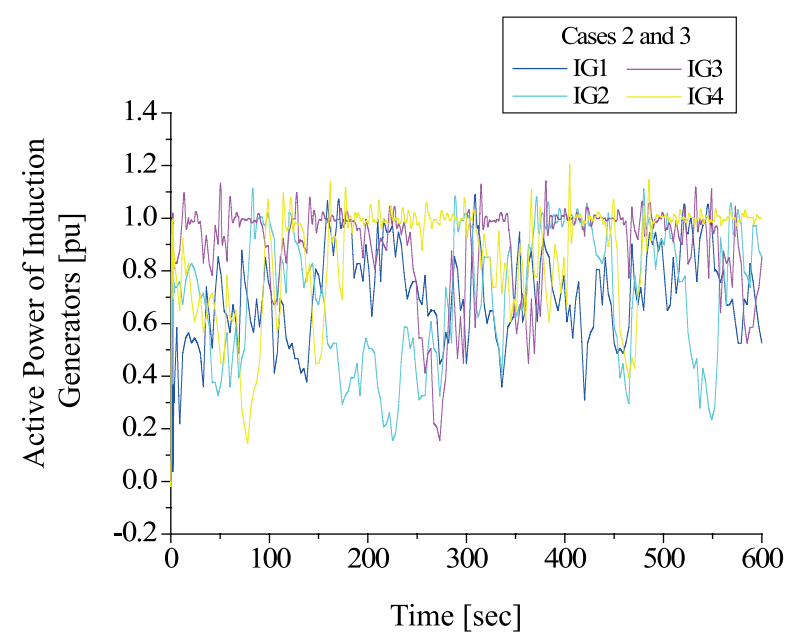

Figure 10. Active Power of Induction Generators (Cases 2 and 3)

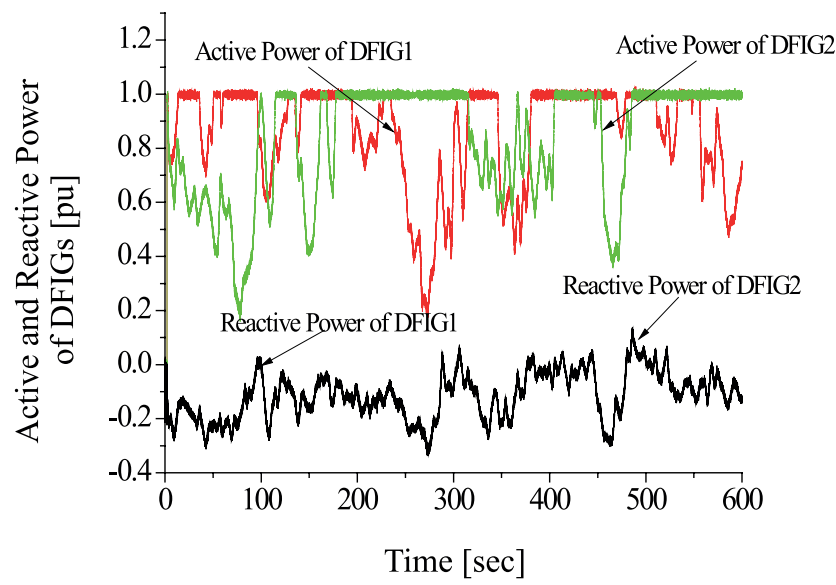

Figure 11. Active and Reactive Power of DFIGs (Case 1)

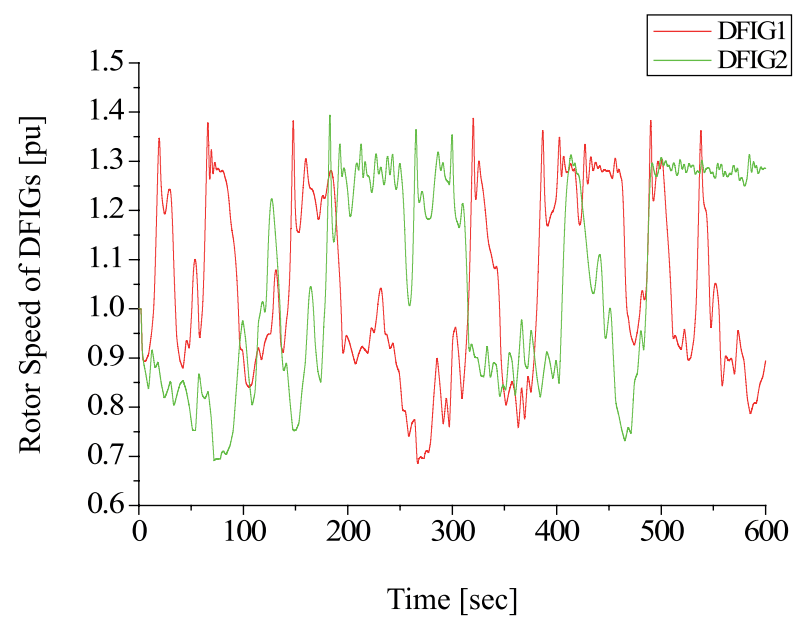

Figure 12. Rotor Speed of DFIGs (Case 1)

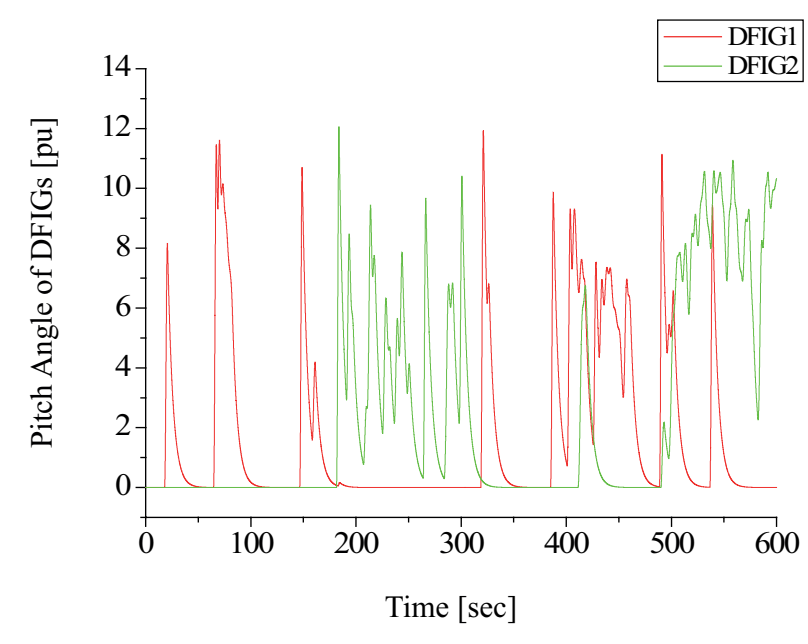

Figure 13. Pitch Angle of DFIGs (Case 1)

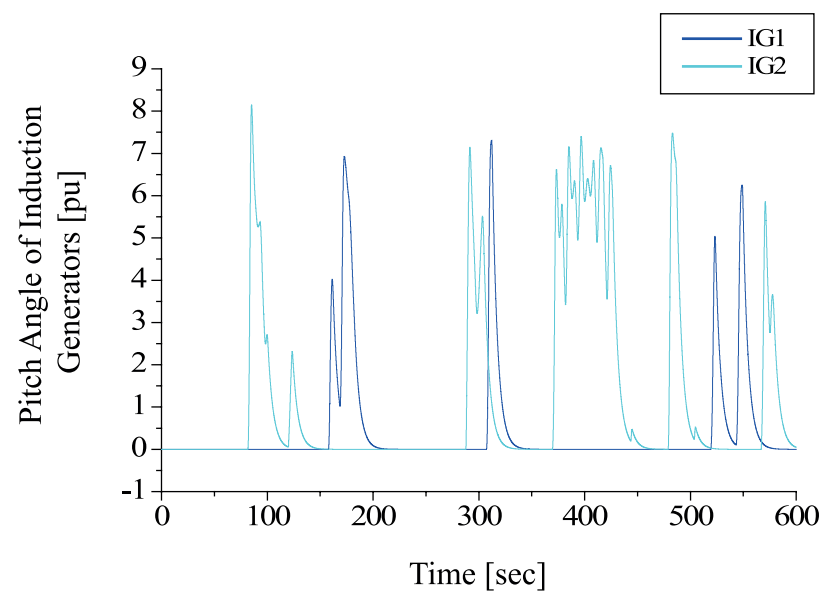

Figure 14. Pitch Angles of Induction Generators (Case 1)

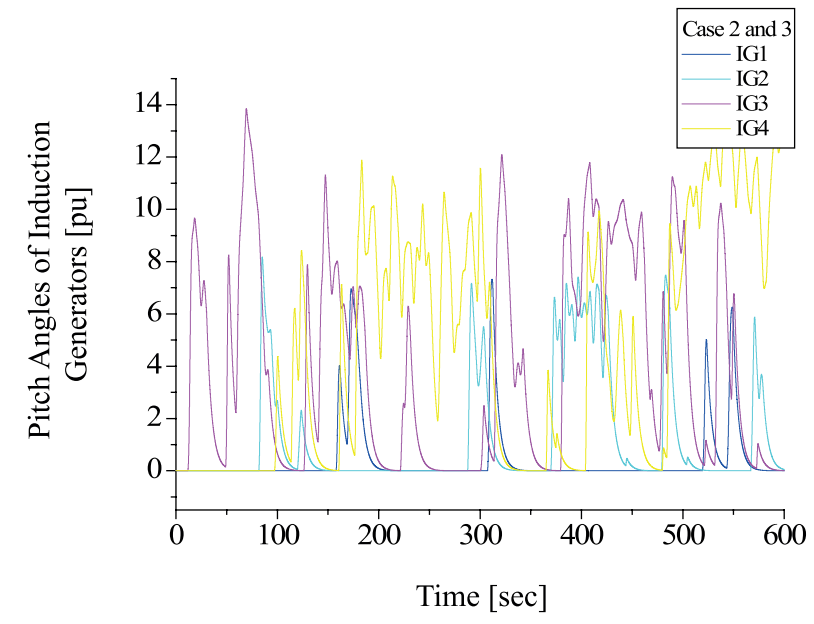

Figure 15. Pitch Angles of IGs (Cases 2 and 3) 


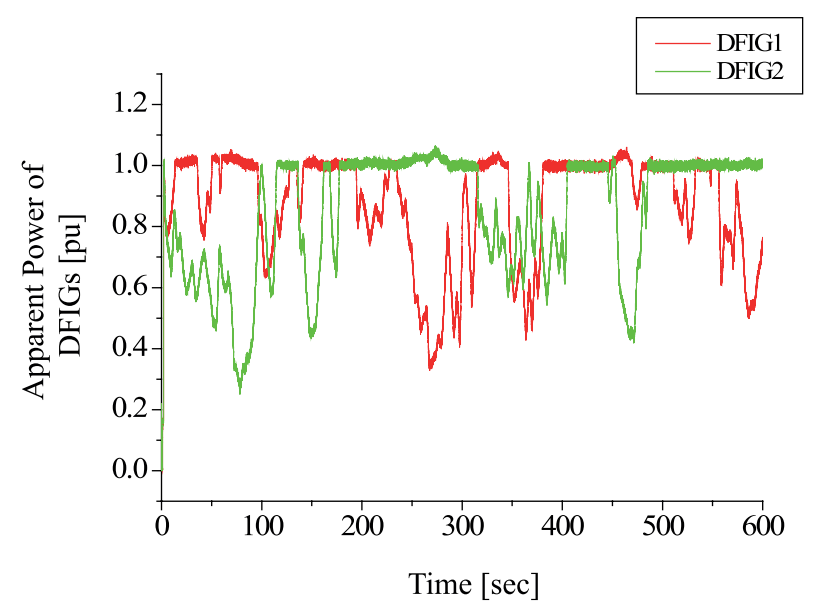

Figure 16. Apparent power of DFIGs (Case 1)

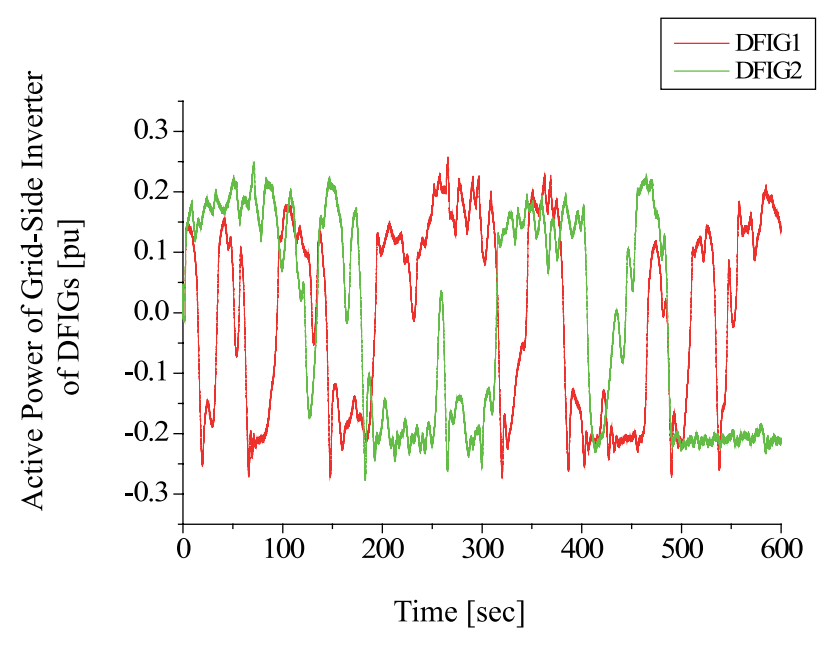

Figure 17. Active Power of Grid-Side Converter of DFIGs (Case 1)

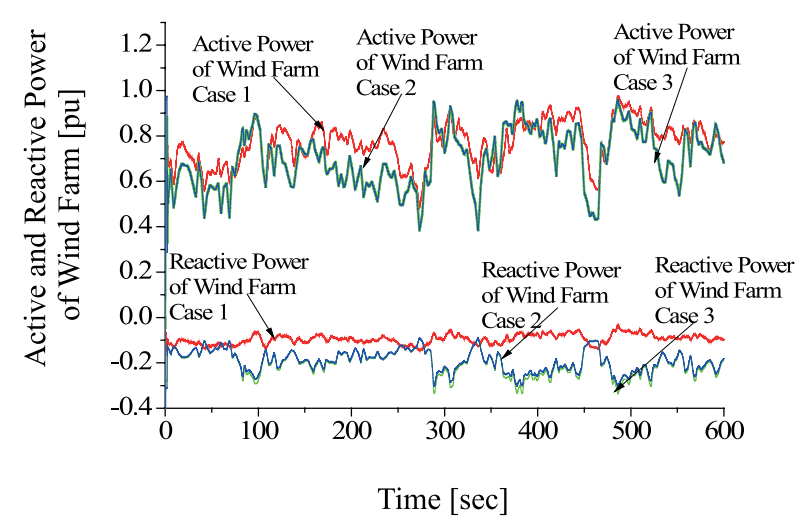

Figure 18. Active and Reactive Power of Wind Farm (Cases 1, 2 and 3)

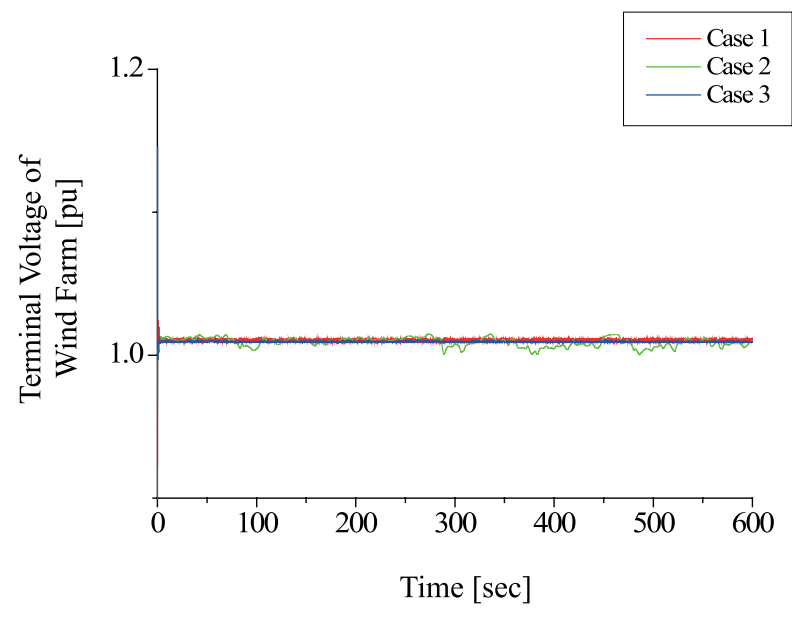

Figure 19. Terminal Voltage of Wind Farm (Cases 1, 2 and 3)

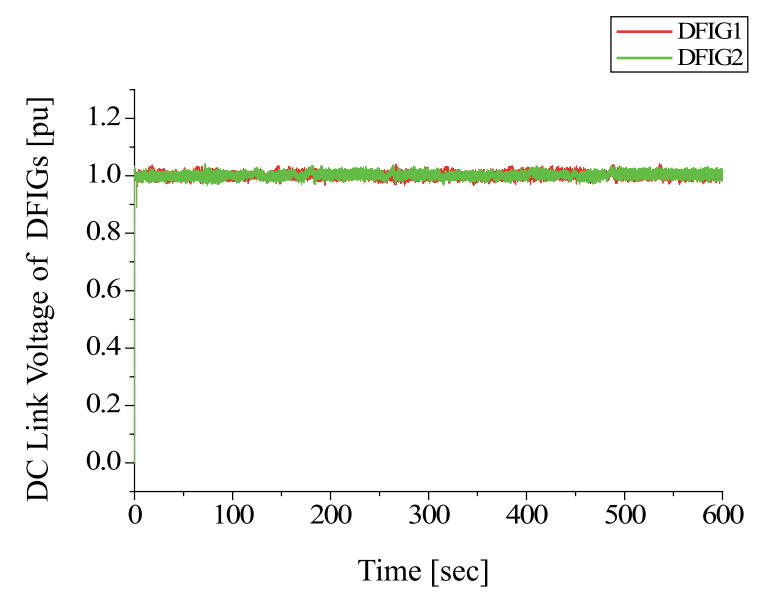

Figure 20. DC Link Voltage of DFIGs (Case 1)

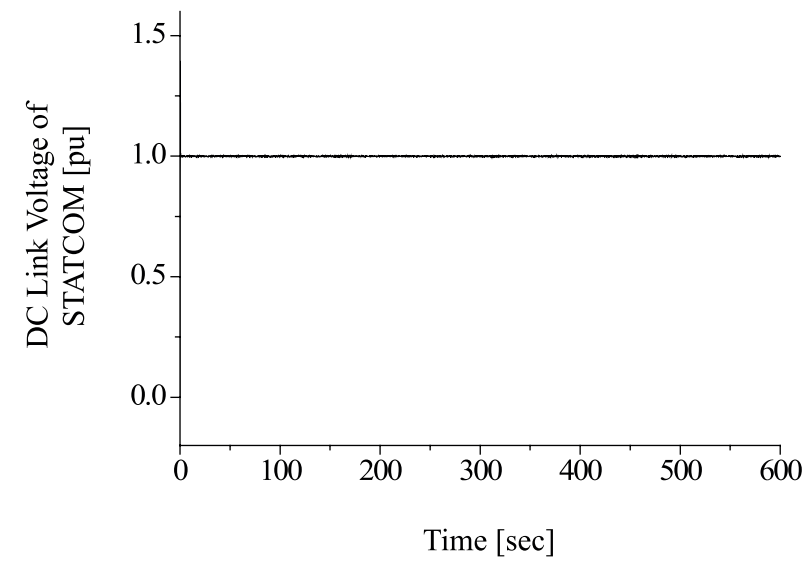

Figure 21. DC Link Voltage of STATCOM (Case 3) 


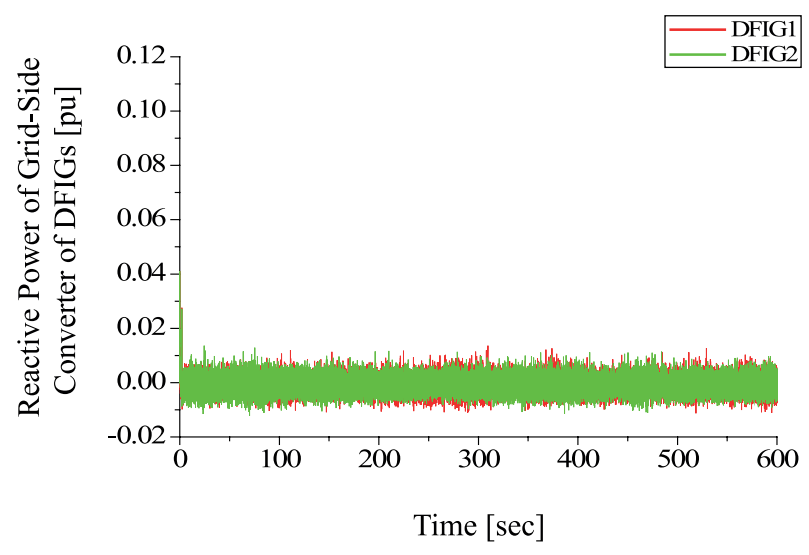

Figure 22. Reactive Power of Grid-Side Inverter of DFIGs (Case 1)

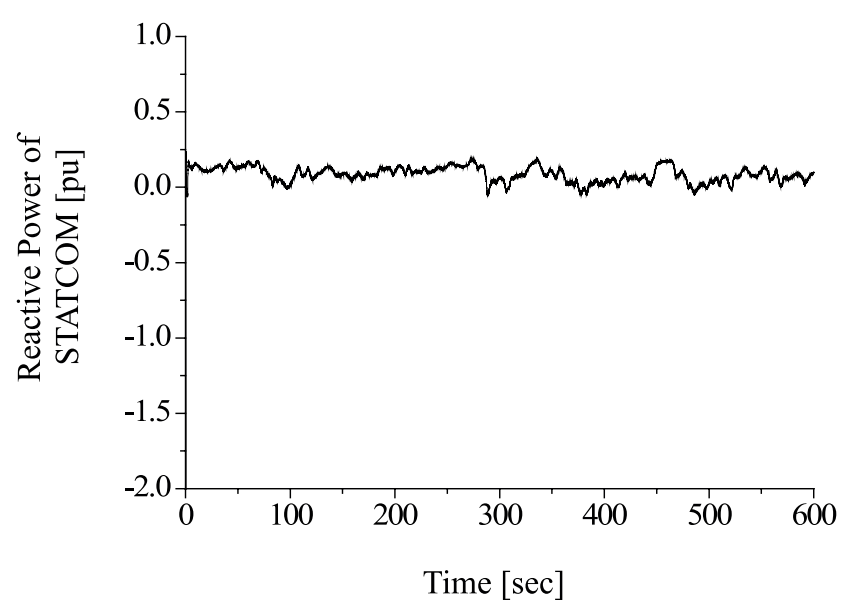

Figure 23. Reactive Power of STATCOM (Case 3)

B) Response of Wind Farm to Grid Fault

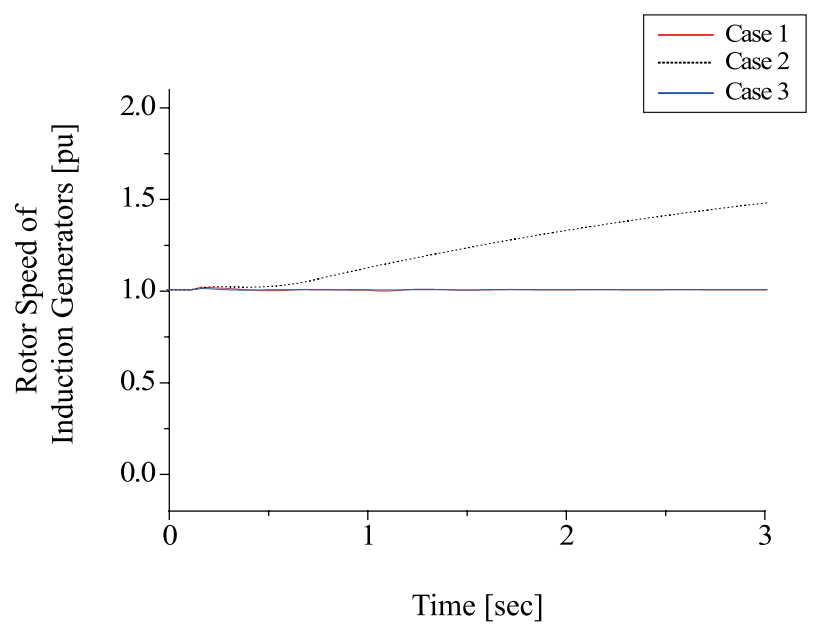

Figure 24. Rotor Speed of Induction Generators (Cases 1, 2 and 3)

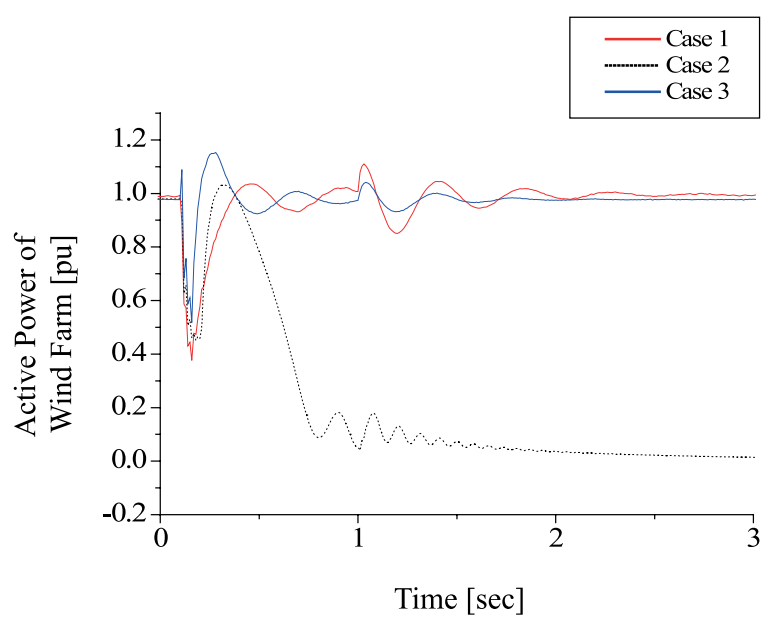

Figure 25. Active power of Wind Farm (Cases 1, 2 and 3)

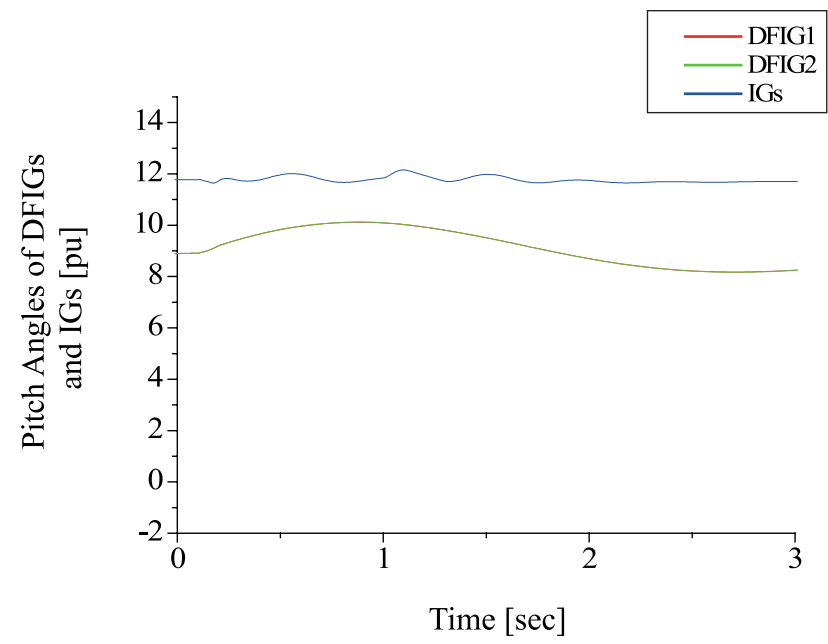

Figure 26. Pitch Angles of DFIGs and IGs (Cases 1)

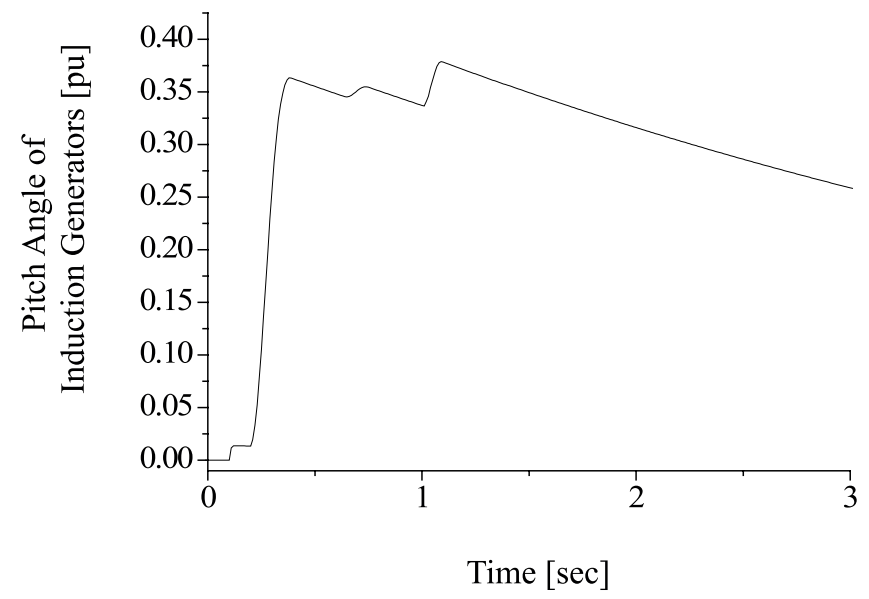

Figure 27. Pitch Angles of IGs (Cases 3) 


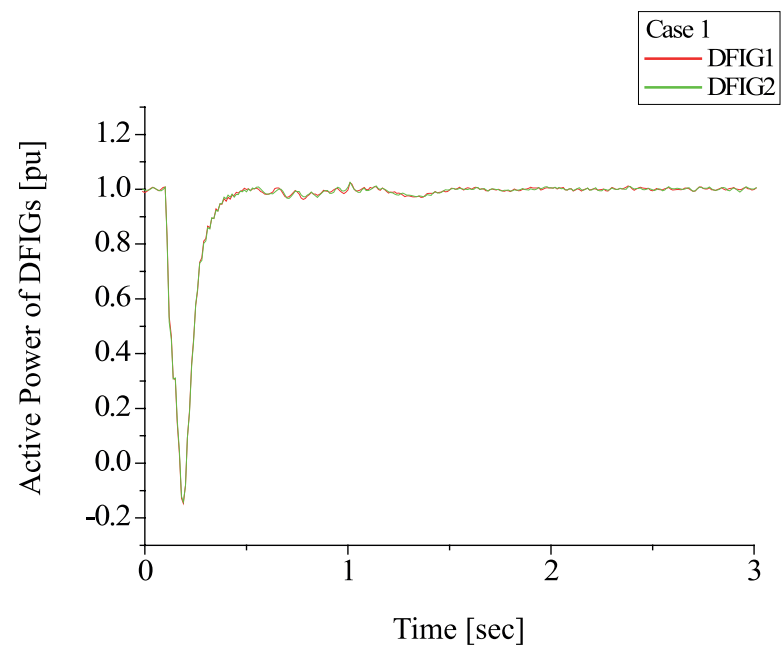

Figure 28. Active Power of DFIGs (Cases 1)

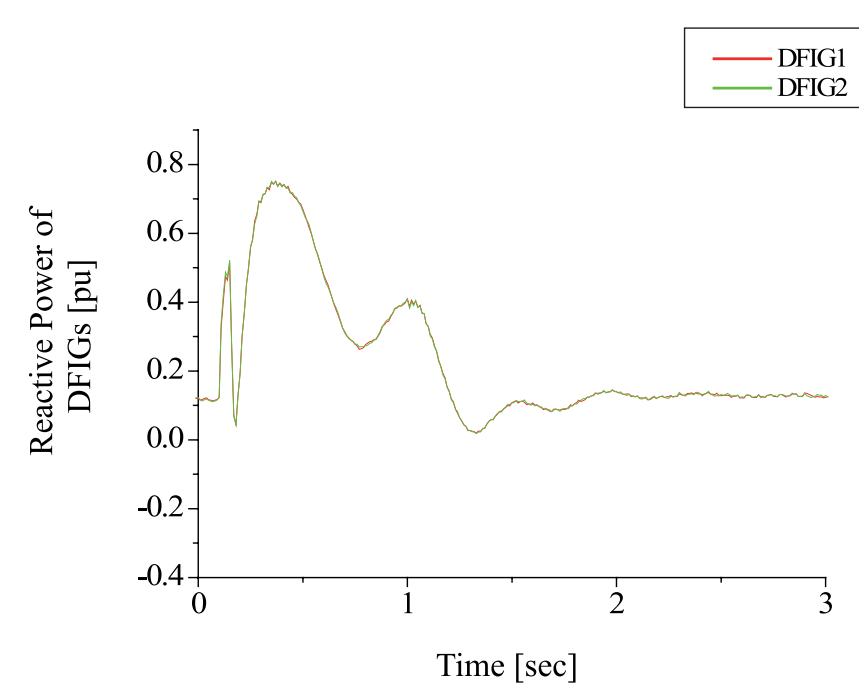

Figure 29. Reactive Power of DFIGs (Cases 1)

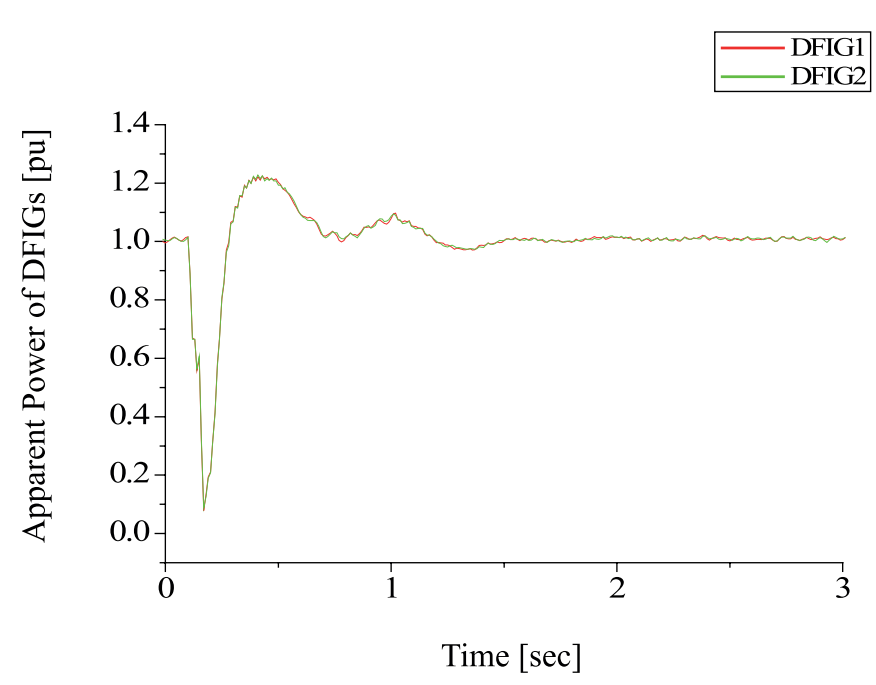

Figure 30. Apparent Power of DFIGs (Cases 1)

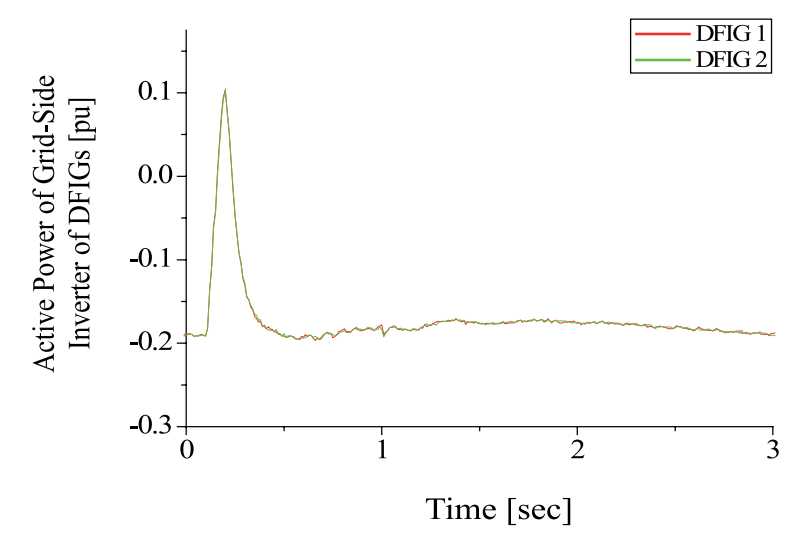

Figure 31. Active Power of Grid-Side Inverter of DFIGs (Cases 1)

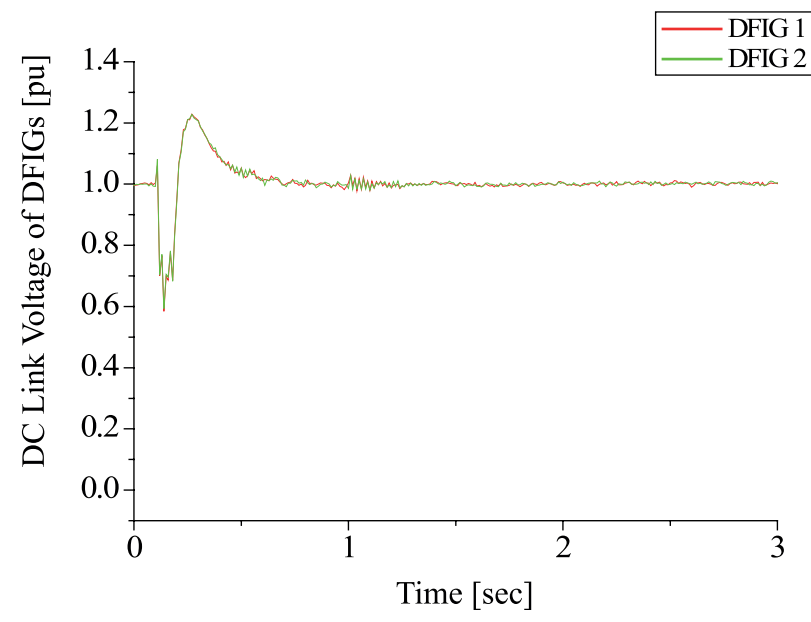

Figure 32. DC Link Voltage of DFIGs (Cases 1)

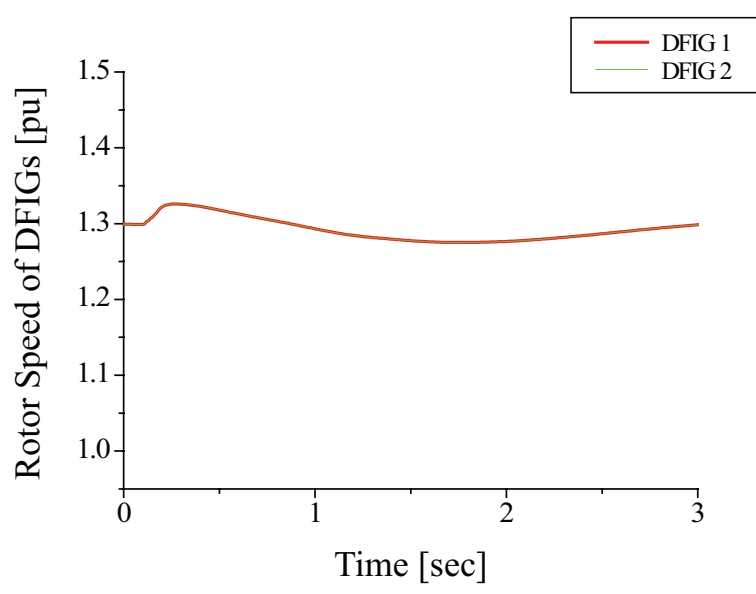

Figure 33. Rotor Speed of DFIGs (Cases 1) 


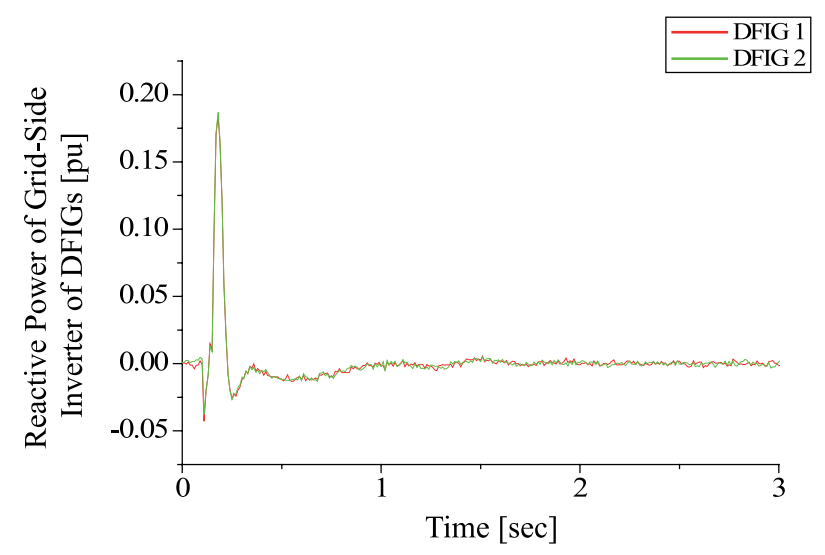

Figure 34. Reactive Power of Grid-Side Inverter of DFIGs (Cases 1)

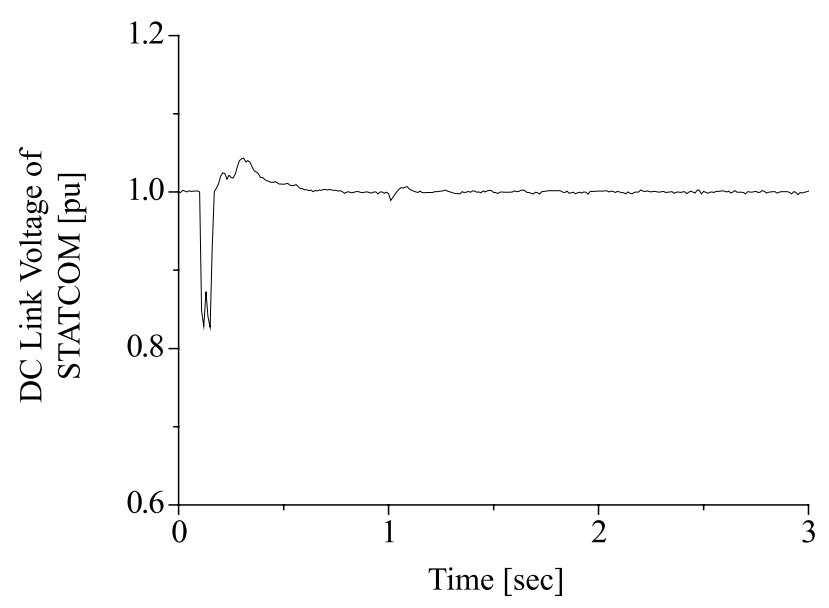

Figure 35. DC Link Voltage of STATCOM (Cases 3)

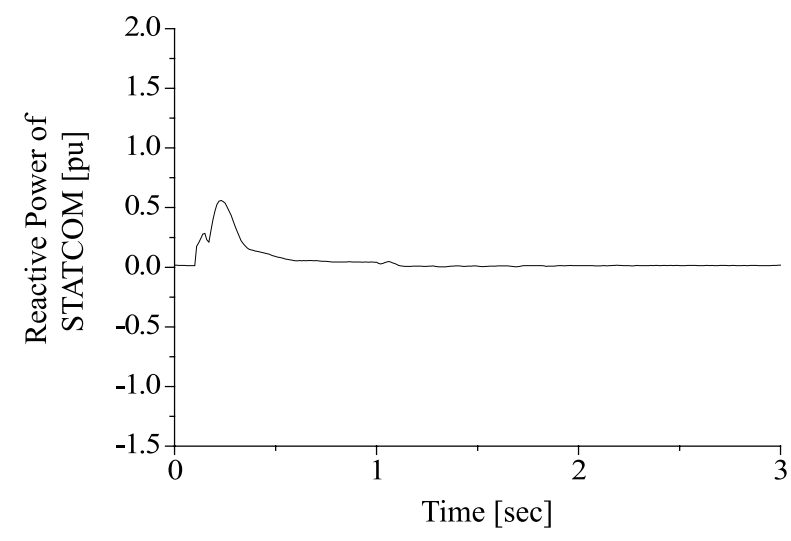

Figure 36. Reactive Power of STATCOM (Cases 3)

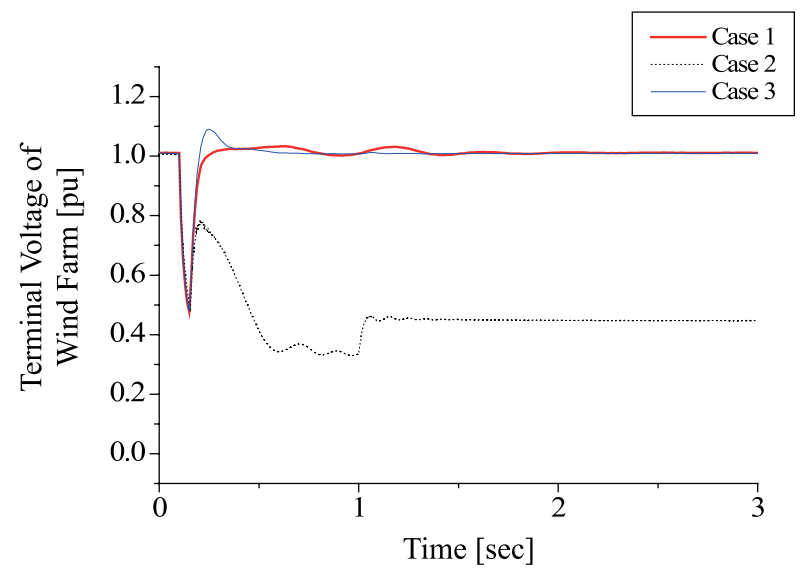

Figure 37. Terminal Voltage of Wind Farm (Cases 1, 2 and 3)

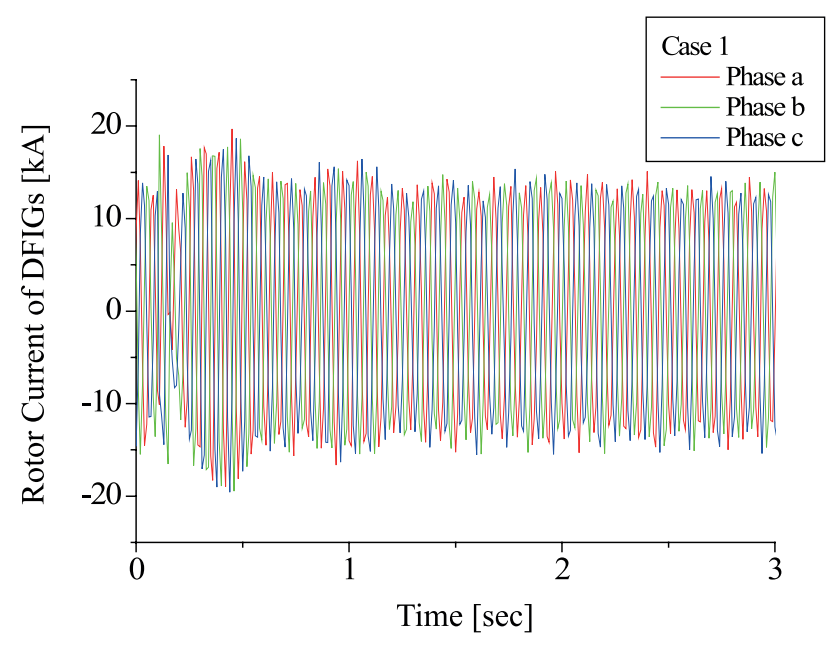

Figure 38. Rotor Current of DFIGs (Cases 1)

\section{Discussion of Results}

Figures 8 shows the variable wind speed data used for the wind generators in all cases considered. Figures 9 and 10 respectively show the active power of the inductions generators for case 1 , 2 and 3. It can be seen from these Figures that the active power of the induction generator follow the nature of the variable wind speed and is not exceeding its limit of 1.0pu at very high speeds, hence showing the effectiveness of the control strategy of the pitch controller of the induction generators.

The effectiveness of the pitch angle controller for the DFIG can be seen in Figures 11 and 12 respectively, where the active power of both DFIGs does not exceed 1.0pu despite the high speed and the rotor speed does not exceeds its maximum designed value of 1.3pu in Figure 4. Also in Figure 11, the DFIGs absorb and supply reactive power from and to the system depending on the nature of the wind speed in order to stabilize the network.

Figures 13, 14 and 15 shows the nature of the pitch controller for DFIGs and the IGs in all the cases, where the pitch controller does not work until the wind speed exceeds the maximum speed 
for the DFIGs and the rated speed for the IGs.

The apparent power of the DFIGs are shown in Figure 16, which confirms that the DFIGs are not overloaded in stabilizing the system, because their apparent power values does not exceed $1.0 \mathrm{pu}$ during the wind speed change. Figure 17 shows the active power of the grid side converter system for the DFIGs in case 1, from which it can be deduce that the maximum limit of $20-30 \%$ of the power processed by the converter which is typical for the DFIG system is not exceeded during the wind speed change.

The active and reactive power of the wind farm is shown in Figure 18 where for case 1 , the active power is higher than case 2 and 3 because 4 generators are operating in case 1(2 DFIG and 2IG), hence a combination of four wind velocity, while in case 2 and 3, only two induction generators are operating. The same applies to the reactive power of the system.

Figures 19, 20 and 21 shows the terminal voltage of the wind farm, DC-link voltage for the DFIGs (case 1) and the DC-link voltage of the STATCOM (case 3) respectively. The reference value of 1.0pu could be seen to be maintained for these Figures showing the effectiveness of the control system applied in all cases. Also, in Figure 19, the terminal voltage of the wind farm is more stable for cases 1 and 3, where a reactive power compensation unit ie, DFIG (case 1) and the STATCOM (case 3) was applied, and the terminal voltage was unstable ie it varies as the wind speed varies in case 2 because no external compensation unit was considered. The reactive power of the grid side converter and the STATCOM supplied to the wind farm to help achieve stability for cases 1 and 3 respectively is shown in Figures 22 and 23.

Figure 24 and 25 gives the transient stability analysis for the rotor speed of the induction generators and the active power of the wind farm for all cases. It can be observed that when reactive power compensation was not considered in case 2 ; the IGs could not stabilize themselves during the grid fault, while in case 1 and
3 , the IGs were stable because, reactive power compensation unit was available in the system. Figure 26 and 27 shows the nature of the pitch control of the DFIGs and the IGs for cases 1 and 3 during the grid fault in order to mitigate the effect of the grid fault on the machines.

The active, reactive, and apparent powers of the DFIGs during the grid fault are shown in Figures 28, 29 and 30 respectively. In all Figures, it can be observed that the DFIG system was able to recover itself after the grid fault to its normal steady state condition because it can provide reactive power of about $75 \%$ (Figure 29) by itself through the help of the frequency converter system. Figures 31, 32 and 33 gives the active power of the inverter, DClink voltage and the rotor speed of the DFIGs during the grid fault, where all this variables was recovered to assume their steady state after the fault in case 1 .

The reactive power supplied by the grid side converter of the DFIGs to the network system to achieve stability during the grid fault is shown in Figure 34 as almost 20\% of the total rating of the DFIG. Figures 35 show the stress of the DC-link voltage due to the grid fault on the STATCOM system for case 3. The STATCOM system was able to recover itself like the DFIG system during grid fault through the provision of reactive power almost $70 \%$ (Figure 36). In Figure 37, the terminal voltage of the wind farm recovered to its steady state for case 1 and 3, because of the reactive power provision from the DFIGs and the STATCOM system respectively. Figure 38 show the nature the rotor current of the DFIG for phases $\mathrm{a}, \mathrm{b}$ and $\mathrm{c}$ respectively in case 1 .

The results show that the DFIGs and the STATCOM (case 1 and 3) systems can effectively stabilize the wind farm by providing sufficient reactive power to the wind farm based on grid codes. However, the DFIGs system seems to be more advantageous because, apart from generating electric power at steady state, it can also stabilize the wind farm.

\section{References}

1. Erlich, H. Wrede and C. Feltes, «Dynamic Behaviour of DFIG-Based Wind Turbine During Grid Faults», IEEJ Trans. Vol. 128, No 4, pp. 396, 2008.

2. Sun, Z. Chen and F. Blaabjerg, «Transient Stability of DFIG Wind Turbines at an External Short Circuit Fault», Wind Energy Journal, Vol. 8, pp. 345-360, 2005.

3. A. D Hasan, G. Michalke, «Fault ride-through capability of DFIG wind turbines», Renewable Energy Vol. 32, pp. 1594-1610, 2007.

4. S. Santos, H. T. Le, «Fundamental time-domain wind turbine models for wind power studies», Renewable Energy, Vol. 32, pp. 2436-2452, 2007.

5. Tomoki Asao, Rion Takahashi, Toshiaki Murata, Junji Tamura, et al, «Smoothing Control of Wind Power Generator Output by Superconducting Magnetic Energy Storage System», Proceeding of International Conference on Electric Machines and Systems 2007, Oct. 8-11, Seoul, Korea.

6. R. Takahashi, J. Tamura, M. Futami, M. Kimura and K. lde, «A New Control Method for Wind Energy Conversion System Using Double Fed Synchronous Generator», 1EEJ Power and Energy, Vol. 126, No. 2, pp. 225-235, 2006 (in Japanese).

7. D. Santos-Martins, S. Arnaltes, J. L. Rodriguez Amenedo, «Reactive power capability of doubly fed asynchronous generators», Electric power systems research, Vol.78, pp. 1837-1840, 2008.

8. E.ON NETZ GmbH, Grid Connection Regulation for High and Extra High voltage, 2006.

9. F. Blaabjerg, F. Iov, K. Ries, «Fuse protection of IGBT Modules against explosions», PCIM Conference, China, 2002.

10. T. Takahashi, «IGBT Protection in AC or BLDC Motor Drives», Technical paper, international rectifier, CA, USA.

11. H. Xie, «Voltage Source Converters With Energy Storage Capability», PhD Thesis, Royal Institute of Technology, School of Electrical Engineering, Division of Electrical Machines and power electronic, Stockholm, 2006.

12. B. H. Chowdhury, S. Chellapilia, «Doubly-fed induction generator control for variable speed wind power generation», Electric Power System Research, Vol. 76, pp. 786-800, 2006.

13. M. Haberberger, F. W. Fuchs, «Novel protection Strategy for current interruptions in IGBT current source inverters», proceedings EPE-PEMC, Norway, 2004.

14. H. Karim-Davijani, A. Sheikjoleslami, H. Livani and M. Karimi-Davijani, «Fuzzy Logic Control of Doubly Fed Induction generator Wind Turbine», World Applied Science Journal, Vol. 6, No. 4, pp. 499-508, 2009.

15. W. Qiao, G. K. Venayagamoorthy, R. G. Harley, «Real-Time Implementation of a STATCOM on a Wind Farm Equipped With Doubly Fed Induction Generators», IEEE Trans. On Industrial Application, Vol. 45, No. 1, 2009.

16. S. M. Muyeen, M. A. Mannan, M. H. Ali, R. Takahashi and J. Tamura, «Stabilisation of wind turbine generator system by STATCOM», IEEJ Trans.PE., Vol. 126-B, No 10, pp.1073-1082, 2006.

17. PSCAD/EMTDC Manual, Manitoba HVDC Research Center, 1994.

18. O. Wasynczuk, D. T. Man, J. P. Sullivan, «Dynamic behaviour of a class of wind turbine generator during random wind fluctuations», 1EEETrans.on Power Apparatus and Systems, Vol.PAS-100, No.6, pp. 2837-2845, 1981. 